УДК 811.111-26+004.4

DOI: 10.6060/BHIISUCT2021_173

Крупина Е.А.

Крупина Екатерина Алексеевна - кандидат филологических наук, Ивановский государственный университет, доцент кафедры иностранных языков.

E-mail: ryabtseva.e.a@yandex.ru.

\title{
ОБРАЗОВАТЕЛЬНЫЕ РЕСУРСЫ СЕТИ ИНТЕРНЕТ В ОБРАЗОВАТЕЛЬНОМ ПРОЦЕССЕ (НА МАТЕРИАЛЕ ПРОЕКТОВ К ДРЕВНЕАНГЛИЙСКОЙ ПОЭМЕ «БЕОВУЛЬФ»)
}

В статье рассматриваются интернет-ресурсы и электронные издания, такие как Beowulf in Hypertext, Gutenberg E-book of Beowulf, Beowulf in Cyperspace, CliffsNotes, Old English Aerobics, a также «Электронный Беовульф» К.Кирнана, созданные для самостоятельного чтения и изучения древнеанглийской поэмы «Беовульф». Особое внимание уделяется образовательным аспектам данных электронных и интернет-пособий.

Ключевые слова: древнеанглийский эпос, Беовульф, электронное издание, образовательный проект, самообразование, дистанционные формы обучения.

\section{Krupina E.A.}

Krupina E.A. - Candidate of Philology, Associate Professor, Ivanovo State University. E-mail: ryabtseva.e.a@yandex.ru.

\section{INTERNET LEARNING RESOURCES IN THE PROCESS OF EDUCATION (BASED ON THE MATERIAL OF STUDY- GUIDES TO THE OLD ENGLISH POEM "BEOWULF")}

The article discusses Internet resources and electronic publications, such as Beowulf in Hypertext, Gutenberg E-book of Beowulf, Beowulf in Cyper-space, CliffsNotes, Old English Aerobics, as well as K. Kiernan's "Electronic Beowulf", created for independent reading and studying the Old English poem "Beowulf". Particular attention is paid to the educational aspects of these electronic and Internet manuals.

Key words: Old English epic literature, Beowulf, electronic edition, learning resource, self-study, distance learning.

Обучение - это целенаправленный процесс двусторонней деятельности обучающего и учащегося по передаче и усвоению знаний [1]. В современном мире основные компоненты процесса обучения (принципы, методы, формы, средства) подвергаются пересмотру, изменению, трансформации. Все большее значение 
приобретает цифровая среда, элементы которой активно внедряются в процесс обучения.

Стремительно развивающимися направлениями информатизации образования при реализации дистанционных форм обучения являются: использование распределенного информационного ресурса глобальной сети, разработка технологий информационного взаимодействия образовательного назначения на базе телекоммуникаций; совершенствование организационных форм, методов и средств обучения на основе реализации дидактических возможностей информационных компьютерных технологий. В работах современных исследователей отмечены позитивные особенности дистанционных форм обучения: независимость получения образования от географического положения и от социально-экономических факторов, уменьшение материальных и временных затрат на обучение, массовость охвата обучающихся, оперативность предоставления участникам процесса обучения учебных материалов, возможность освоения обучающимися индивидуальных учебных программ при методическом сопровождении процесса обучения педагогами высокой квалификации за счет осуществления удаленного информационного взаимодействия учебного назначения и использования учебных материалов, представленных в электронном виде. Вместе с тем, ряд авторов отмечает, что современная реализация дистанционного обучения имеет ряд недостатков, к которым можно отнести: нерегулярность применения средств автоматизации при управлении процессом обучения; хаотичность информационного взаимодействия между обучающими, обучаемыми и интерактивным образовательным ресурсом; неадекватность способов представления учебных материалов возможностям современных ИКТ. В исследованиях подчеркивается, что дистанционное обучение реализуется с использованием электронных учебных материалов (электронных образовательных ресурсов, электронных изданий учебного назначения, электронных средств учебного назначения и др.), в том числе иллюстрированных гипертекстовых и мультимедийных учебных пособий, интерактивных практикумов, тестовых систем, электронных словарей и энциклопедий, которые применяются при обучении и организации учебного процесса $[2$, c. 5-6] .

В мировой практике эффективность образования тесно связана с идеями гуманизации, индивидуализации, дифференциации на всех уровнях образовательного процесса. На первый план в познавательном процессе выходит личность ученика, в этом случае роль учителя не сводится лишь к передаче знаний. Главным в деятельности учителя или преподавателя становится организация познавательной деятельности учащихся с учетом их способностей и индивидуальных возможностей. Происходит трансформация парадигмы «учитель - учебник - ученик» на «ученик - учебник учитель», где акцент смещается на самостоятельную деятельность учащихся, взаимодействие учеников между собой. Кроме того, современный человек должен уметь мыслить самостоятельно, принимать обдуманные решения. Таким образом, современная система образования должна отвечать нескольким требованиям, не только давать знания и организовывать процесс обучения, но и предоставлять учащимся возможность размышлять, сопоставлять, анализировать, а также формулировать и аргументировать собственную точку зрения. С этого угла зрения электронные средства обучения могут являться дополнительным средством к традиционным учебникам для реализации этой задачи обучения. Задачи современной дидактики могут быть успешно решены с помощью электронных учебников, а также гипертекстовых технологий. Система ссылок позволяет учащемуся познакомиться с проблемой с разных точек зрения, сделать собственные выводы, найти подтверждение или опровержение тем или 
иным теориям, утверждениям и т.д. Для этого необходимо тщательно отбирать источники, к которым учащийся обращается в процессе обучения [3, с. 29-36] .

Таким образом, особую роль в данной ситуации начинает играть преподаватель или учитель как наставник, который умело направляет деятельность учащегося. Особое значение приобретает работа преподавателя с онлайн ресурсами, электронными изданиями, их разработка, анализ.

В последние десятилетия живой интерес вызывают произведения древнеанглийского периода. «Беовульф» - древнеанглийская поэма, время создания которой относят к VIII веку. Это крупнейшая поэма англосаксонского эпоса, чей манускрипт полностью сохранился до наших времен. Это произведение представляет интерес не только с точки зрения понимания истории, культуры англосаксов, но и с точки зрения литературных стилей, художественных средств. Поэма изучалась как исторический памятник, хранитель событий времен англосаксов. Лекция крупнейшего исследователя «Беовульфа» Дж. Толкина стала искрой для всеобъемлющего процесса изучения поэмы как памятника литературы. Рукопись поэмы была найдена в начале XVIII века исландским ученым Г. Торкелиным, который подготовил два списка поэмы. В 1815 году поэма впервые была опубликована. С этого времени произведение тщательно изучалось различными учеными: лингвистами, филологами, историками, литературоведами. Были созданы многочисленные переводы «Беовульфа» на современный английский. Среди них выделяются работы, выполненные Уильямом Моррисом (1895) и Шеймасом Хини (1999). Оксфордский учёный Толкин вдохновлялся мотивами древнеанглийской поэмы при создании трилогии «Властелин колец».

Первый и единственный полный перевод поэмы с англосаксонского на русский был сделан Владимиром Тихомировым и впервые опубликован в 1975 году. Эта работа отличается тем, что автор предпринял успешную попытку передать особенности аллитерационного стиля в русском переводе.

По мотивам поэмы написаны романы Дж. Гарднера «Грендель» и М. Крайтона «Пожиратели плоти». В первом из них события поэмы изложены с точки зрения противоположной стороны - чудовища.

Древнеанглийская поэма входит в курс изучения истории английского языка. Лингвисты, филологи, медиевисты проводят исследования данного произведения, чтобы более детально изучить поэму с лингвистической, литературоведческой и исторической точек зрения. Игры, фильмы, книги по мотивам древнеанглийского произведения популярны сейчас среди молодежи. В сети Интернет можно обнаружить как развлекательные, так и образовательные ресурсы по данному произведению, отвечающие запросам различных категорий пользователей. Текст древнеанглийской поэмы содержится во многих авторитетных цифровых библиотеках (British Library, archive.org и др.) Множество образовательных ресурсов предлагает читателю познакомится с текстом поэмы на древнеанглийском языке, на современном английском языке и на других языках в переводе. Так, онлайн pecypc Poetry Foundation предлагает текст поэмы на древнеанглийском языке, Open Culture предлагает прослушать текст на древнеанглийском языке.

В сети интернет обучающийся может найти различные ресурсы, которые необходимо проанализировать и оценить их эффективность и плоскость применения. На примере электронных образовательных проектов к древнеанглийской поэме «Беовульф» можно проследить степень разнообразия и широту охвата материалов к этому произведению. Интернет-ресурс Beowulf in Hypertext содержит вариант текста поэмы на древнеанглийском языке, на современном английском языке, описание групп персонажей, как то: Грендель, гауты, даны и др. Вкладка История раскрывает основные 
проблемы, связанные с манускриптом, а именно: авторство, археологические находки и культура англосаксов, христианские мотивы в поэме. Отдельный раздел выделен для ссылок на интернет-ресурсы, которые содержат информацию о древнеанглийской поэме. На сайте есть возможность поиска отрывков текста произведения. Данный ресурс не разработан полностью, некоторые ссылки не валидны. Однако составители включили основную необходимую информацию о данном произведении.

Интернет-проект Gutenberg eBook of Beowulf - бесплатный ресурс для жителей США и других стран. Пользователи могут копировать, пересылать информацию проекта в соответствии с правилами ресурса.

Текст представляет собой проверенную версию четвертого издания поэмы Харрисона, Шарпа, которое включает оригинальный текст с некоторыми исправлениями в орфографии.

Интерфейс проекта прост и удобен для пользователей. Правая часть страницы содержит рамку навигации со ссылками на отдельные главы и разделы сайта. Одним «кликом» мыши читатель может перейти на страницу с предисловием или любой другой раздел. Наполнение сайта отражено в содержании и включает предисловие, непосредственно текст поэмы на древнеанглийском языке, текст поэмы «Битва при Финнбурге», раздел посвященный именам собственным (своеобразный ономастикон), раздел комментариев, глоссарий и раздел с указанием выполненных исправлений.

Beowulf on Steorarume (Beowulf in Cyberspace) - интернет-ресурс Б. Слэйда, профессора университета штата Юта. Данный сайт представляет собой систематизированную информацию о поэме. Текст поэмы на древнеанглийском языке, перевод на современный, выполненный Б. Слэйдом на основе манускрипта англосаксонского произведения и с использованием материалов проекта «Электронный Беоульф» К. Кирнана.

На сайте информация представлена компактно и в удобной для пользователя форме, навигация проста и понятна. Интерфейс сайта содержит ссылки на материалы к поэме: структура произведения, проблема датировки и авторства текста, глоссарий, своего рода энциклопедия с иллюстрациями, карты местности и генеалогии, библиографический список, ссылки на дополнительные тексты на древнеанглийском и материалы к ним, а также перевод древнеанглийского текста поэмы на современный немецкий язык, незавершенный раздел перевод «Беовульфа» на хинди.

Интернет-проект CliffsNotes - часть образовательного проекта Houghton Mifflin Harcourt - включает не только глоссарий, но и различную дополнительную информацию о поэме: краткое содержание, основные обсуждаемые вопросы о произведении (дата создания и фиксации на письме, вопрос определения жанра, вопрос об авторстве, исторического и реального в Беовульфе, художественные средства, анализ личностей главного героя Беовульфа, Виглафа, Гренделя, матери Гренделя, Хротгара, Унферта, Вальхтеов, карта взаимоотношений главных персонажей, проблема авторства, рукопись поэмы, основные мотивы в Беовульфе с точки зрения литературных критиков, символизм, викторина на знание художественного произведения, состоящая из 13 вопросов, известные цитаты из «Беовульфа» на современном английском языке, фильмография (довольно краткая), вопросы для создания эссе, предложения по проектам на основе древнеанглийской поэмы, глоссарий.

Электронный проект Old English Aerobics на своем сайте предлагает справочное издание к древнеанглийской поэме «Беовульф». Данный сайт содержит дополнительные материалы к работе П.С. Бейкера "Introduction to Old English". Материалы включают онлайн версии всех текстов из книги, упражнения и глоссарий. 
Один из крупнейших исследователей «Беовульф» К.Кирнан создал проект «Электронный Беовульф». На сайте университета штата Кентуки представлено четвертое издание «Электронного Беовульфа», бесплатная он-лайн версия. Составители отмечают, что данный ресурс отвечает потребностям широкого круга пользователей, которым требуется полный построчный перевод; студентов, изучающим поэму; а также ученых, которые хотят получить доступ ко всему объему информации о произведении. Начало проекта «Электронный Беовульф» было положено в 1993, когда профессор К. Кирнан, долгое время занимавшийся историей рукописи поэмы, использовал новые технологии, чтобы представить взгляд с другой стороны на текст произведения. Данное издание «Электронного Беовульфа» включает огромную базу цифровых изображений, около двух тысяч утерянных вариантов текстов, отреставрированных с помощью более ранних записей, а также с помощью новых технологий на основе ультрафиолета, оптоволокна и цифровых изображений. На каждое слово в издании есть ссылка к глоссарию, где, в свою очередь, отражаются полная строка текста манускрипта и место ее нахождения вместе с толкованием. Ко всему прочему, у читателей есть доступ к электронным оригиналам Коттонского собрания и его частям, к рукописи текста 18 века Г. Торкелина, а также к основанным на его рукописи 1815 года экземплярах Дж. Конибэра и сэра Ф. Мэдена. Сайт университета содержит подробную инструкцию по пользованию электронного издания К.Кирнана, которое можно приобрести на компактдисках.

Вышеперечисленные образовательные ресурсы предлагают обширный спектр материалов к произведению: от непосредственно текста поэмы, его переводов, материалов литературных критиков, энциклопедий и глоссариев до разработанных упражнений и викторин по произведению. Необходимо отметить, что многие ресурсы находятся на стадии разработки и постоянно дополняются новой информацией. Отличительными особенностями данных ресурсов является их образовательная направленность, широкий охват материалов (иногда на нескольких языках), удобный интерфейс и навигация, четкая и понятная структура сайтов, включение наглядных иллюстраций, аудио- и видеоматериалов.

\section{СПИСОК ЛИТЕРАТУРЫ}

1. Крысько В. Г. Психология и педагогика: учебник для бакалавров. М.: Издательство Юрайт, 2019. 471 с.

2. Лапенок М.В. Научно-педагогические основания создания и использования электронных образовательных ресурсов информационной среды дистанционного обучения (на примере подготовки учителей): дис. ... док. пед. наук. М., 2014. 392 с.

3. Новиков А.H. Формы обучения в современных условиях. URL: http://www.anovikov.ru/artikle/forms.htm (дата обращения: 2.05.2021).

4. Beowulf in Hypertext. URL: https://www.humanities.mcmaster.ca/ beowulf/main.html (дата обращения: 3.05.2021).

5. CliffsNotes. URL: https://www.cliffsnotes.com/literature/b/beowulf/study-help/full-glossaryfor-beowulf (дата обращения 16.01.2021).

6. Electronic Beowulf. URL: http://ebeowulf.uky.edu/\#studyingbeowulf (дата обращения: 2.05.2021).

7. Gutenberg. URL: https://www.gutenberg.org/files/9700/9700-h/9700-h.htm (дата обращения: 3.05.2021).

8. Beowulf on Steorarume. URL: https://heorot.dk (дата обращения: 3.05.2021).

9. Old English Aerobics. URL: http://www.oldenglishaerobics.net/beowulf.html (дата обращения: 3.05.2021).

10. Open Culture. URL: https://www.openculture.com/2014/10/hear-beowulf-read-in-theoriginal-old-english.html (дата обращения: 28.04.2021). 
11. Poetry Foundation. URL: https://www.poetryfoundation.org/poems/43521/beowulf-oldenglish-version (дата обращения: 28.04.2021).

\section{REFERENCES (TRANSLITERATED)}

1. Krys'ko V.G. Psikhologiya i pedagogika: uchebnik dlya bakalavrov. M.: Izdatel'stvo Yurait, 2019. $471 \mathrm{~s}$.

2. Lapenok M.V. Nauchno-pedagogicheskie osnovaniya sozdaniya i ispol'zovaniya elektronnykh obrazovatel'nykh resursov informatsionnoi sredy distantsionnogo obucheniya (na primere podgotovki uchitelei): dis. ... dok. ped. nauk. M., 2014. $392 \mathrm{s.}$

3. Novikov A.N. Formy obucheniya $\mathrm{v}$ sovremennykh usloviyakh. URL: http://www.anovikov.ru/artikle/forms.htm (data obrashcheniya: 2.05.2021).

4. Beowulf in Hypertext. URL: https://www.humanities.mcmaster.ca/ beowulf/main.html (data obrashcheniya: 3.05.2021).

5. CliffsNotes. URL: https://www.cliffsnotes.com/literature/b/beowulf/study-help/full-glossaryfor-beowulf (data obrashcheniya 16.01.2021).

6. Electronic Beowulf. URL: http://ebeowulf.uky.edu/\#studyingbeowulf (data obrashcheniya: 2.05.2021).

7. Gutenberg. URL: https://www.gutenberg.org/files/9700/9700-h/9700-h.htm (data obrashcheniya: 3.05.2021).

8. Beowulf on Steorarume. URL: https://heorot.dk (data obrashcheniya: 3.05.2021).

9. Old English Aerobics. URL: http://www.oldenglishaerobics.net/beowulf.html (data obrashcheniya: 3.05.2021).

10. Open Culture. URL: https://www.openculture.com/2014/10/hear-beowulf-read-in-theoriginal-old-english.html (data obrashcheniya: 28.04.2021).

11. Poetry Foundation. URL: https://www.poetryfoundation.org/poems/43521/beowulf-oldenglish-version (data obrashcheniya: 28.04.2021).

Поступила в редакцию 27.05.2021 г. Принята к публикации 30.06.2021 г.

\section{Для циитирования:}

Крупина Е.А. Образовательные ресурсы сети интернет в образовательном процессе (на материале проектов к древнеанглийской поэме «Беовульф») // Вестник Гуманитарного института. 2021. №2. С. 173-178.

URL: https://isuct-bhi.ru/sites/default/files/issue/2021/1/bhi-2021-1-173.pdf 